\title{
Bio-engineered graphene oxide microcomposites containing a metabolically versatile Paracoccus sp. MKU1 for enhanced catechol degradation
}

\author{
Manikka Kubendran Aravind ${ }^{1}$, Jincymol Kappen², Perumal Varalakshmi \\ Swamidoss Abraham John², Balasubramaniem Ashokkumar 1* \\ ${ }^{\mathbf{1}}$ Department of Genetic Engineering, School of Biotechnology, \\ Madurai Kamaraj University, Madurai, Tamil Nadu, INDIA. \\ ${ }^{2}$ Centre for Nanoscience and Nanotechnology, Department of Chemistry, \\ Gandhigram Rural Institute, Gandhigram, Tamil Nadu, INDIA. \\ ${ }^{3}$ Department of Molecular Microbiology, School of Biotechnology, \\ Madurai Kamaraj University, Madurai, Tamil Nadu, INDIA.
}

\footnotetext{
*Corresponding author

Balasubramaniem Ashokkumar

Department of Genetic Engineering, School of Biotechnology, Madurai Kamaraj University, Madurai - 625 021, INDIA.

Tel: (91) 452-2459105

FAX: (91) 452-2459115

EMAIL: rbashokkumar@yahoo.com
} 
Supporting information

Figure S1. The ortho- and meta cleavage pathways in aerobic catabolism of catechol. 1) Catechol 1, 2 dioxygenase; 2) Muconate cycloisomerase; 3) Muconolactone D-isomerase; 4) Oxoadipate enol-lactonase; 5) 3-Oxoadipate CoA-transferase; 6) Catechol 2, 3 dioxygenase; 7) 2Hydroxymuconic semialdehyde hydrolase; 8) 2-Oxo-penta 4-enoate hydratase; 9) 4-hydroxy 2oxovalerate aldolase.


Aghapour et al., 2013 
Supporting information

Figure S2. A) AFM and B) SEM images of graphene oxide.

A

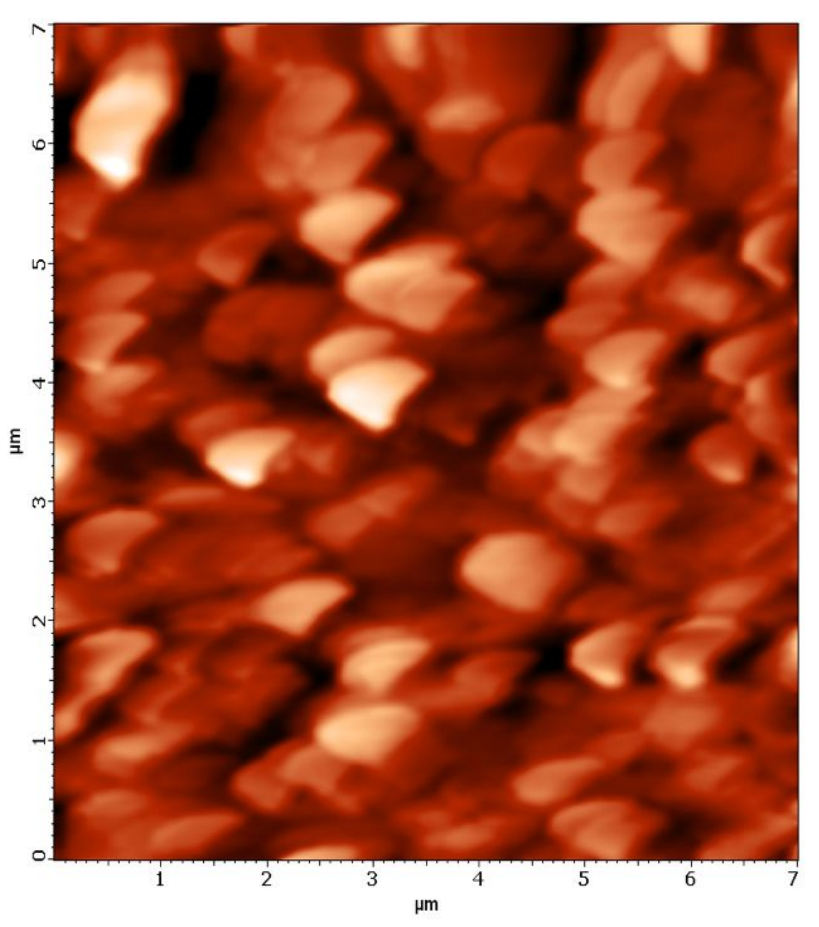

B

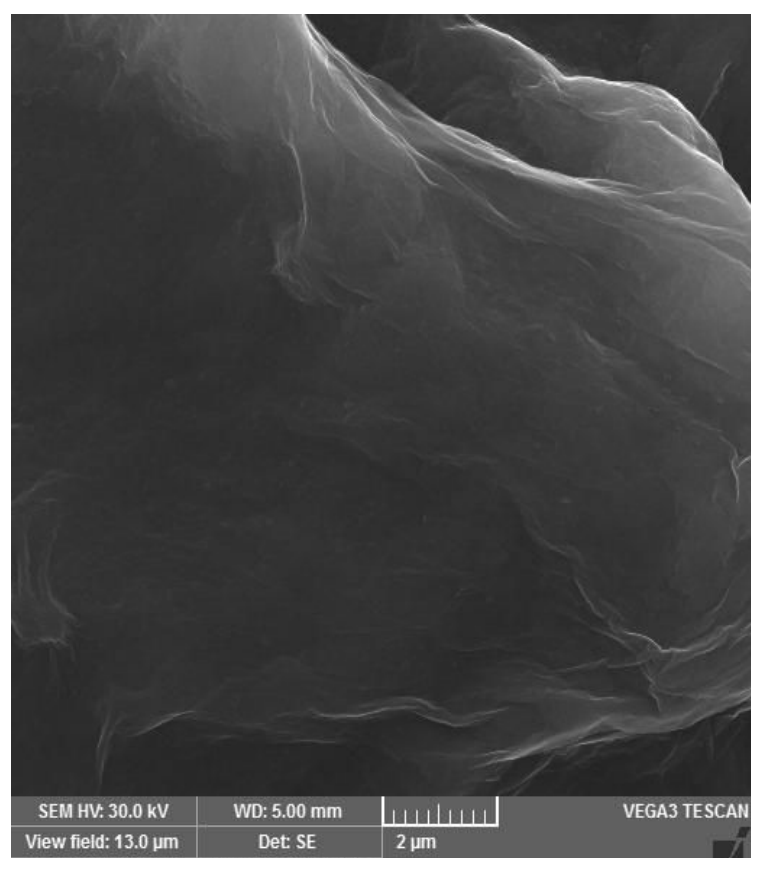


Figure S3. HPLC analysis for quantitative determination of catechol degradation at $24 \mathrm{~h}$. (A) Catechol standard (B) Catechol degradation by free Paracoccus sp. MKU1 (C) Catechol adsorption by PGO (D) Catechol degradation by PGO immobilized Paracoccus sp. MKU1.

A

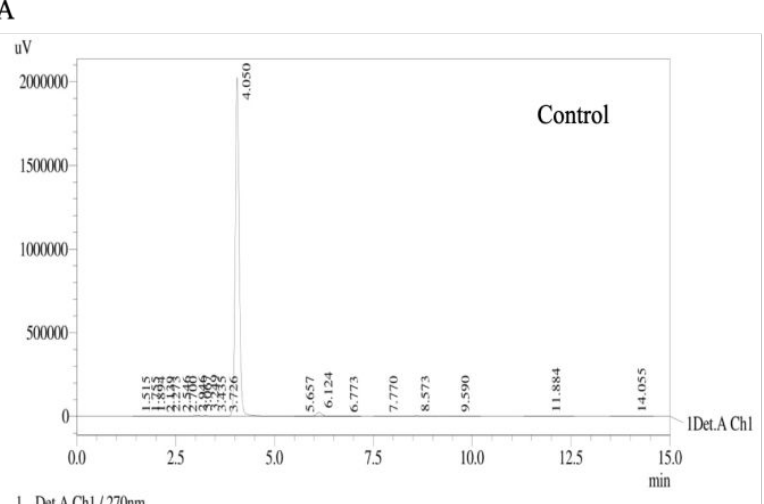

1 Det.AChl $/ 270 \mathrm{~nm}$

$\mathrm{C}$

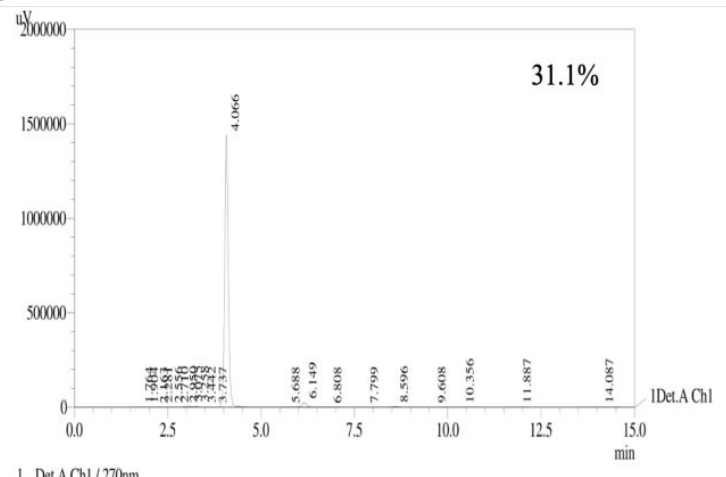

B

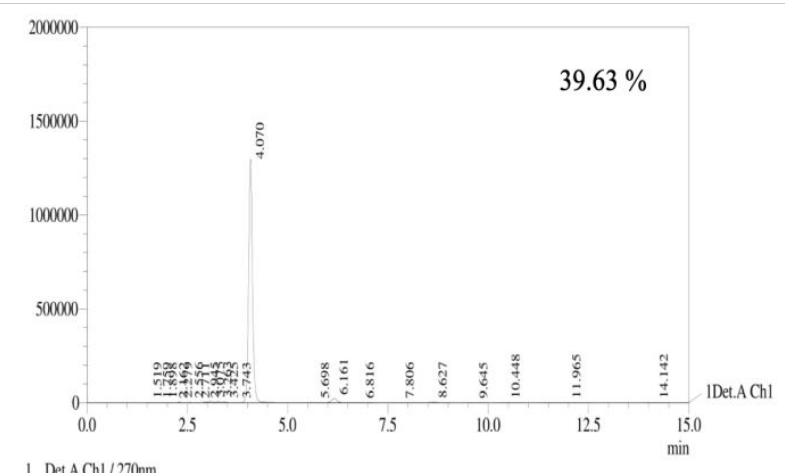

1 Det.AChl $/ 270 \mathrm{~nm}$

D

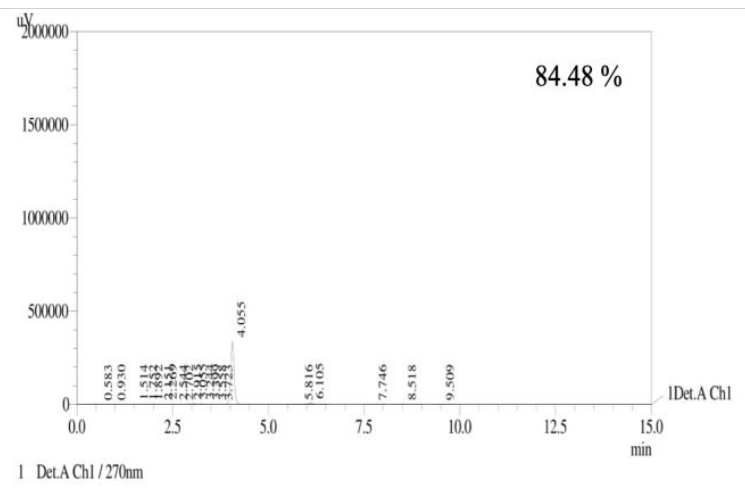


Figure S4. Relative plot for OD vs CFU of Paracoccus sp. MKU1. Paracoccus sp. MKU1 grown in minimal media containing catechol was harvested at different time intervals and OD was measured at $600 \mathrm{~nm}$. The bacterial samples were diluted and plated to count CFUs.

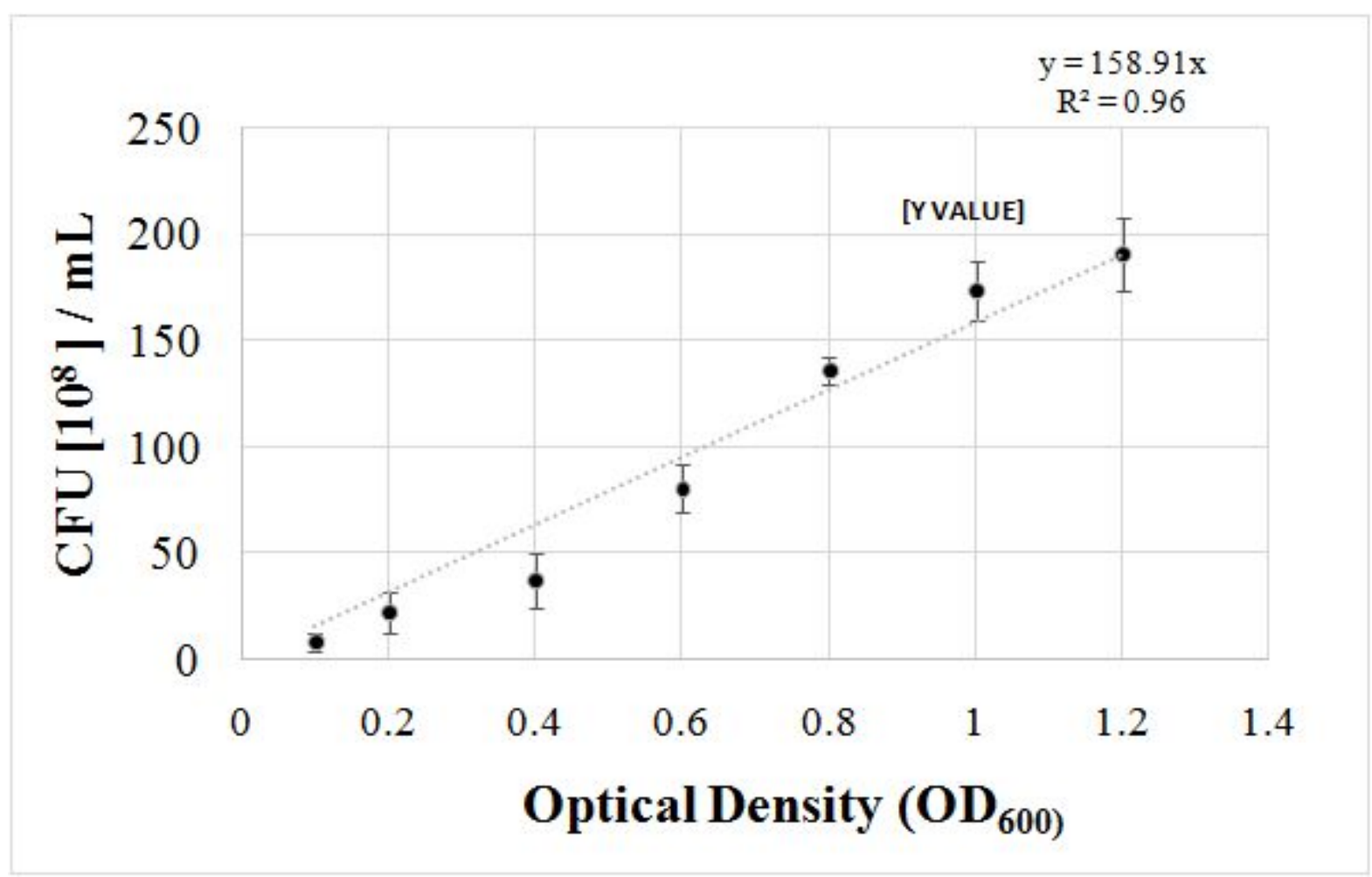

